\title{
Reducing Fault Current by Using FACTS Devices to Improve Electrical Power Flow
}

\author{
Ibrahim M. Mehedi $\mathbb{D}^{1,2}$ Jahin Al Hasan Joy $\mathbb{D}^{3},{ }^{3}$ Md. Rafiqul Islam $(\mathbb{D}),{ }^{3}$ Nayeema Hasan (iD), \\ Ubaid M. Al-Saggaf $\left(\mathbb{D},{ }^{1,2}\right.$ Ahmad H. Milyani ${ }^{1 D},{ }^{1}$ Ahmed I. Iskanderani ${ }^{1}$, ${ }^{1}$ \\ Abdullah Abusorrah $\mathbb{D}^{1},{ }^{1,4}$ Muhyaddin Rawa $\mathbb{D}^{1,4}$ and Hussain Bassi $\mathbb{D}^{1,4}$ \\ ${ }^{1}$ Department of Electrical and Computer Engineering (ECE), King Abdulaziz University, Jeddah 21589, Saudi Arabia \\ ${ }^{2}$ Center of Excellence in Intelligent Engineering Systems (CEIES), King Abdulaziz University, Jeddah 21589, Saudi Arabia \\ ${ }^{3}$ Department of Electrical and Electronic Engineering, Khulna University of Engineering \& Technology, \\ Khulna, Bangladesh \\ ${ }^{4}$ Center of Research Excellence in Renewable Energy and Electrical Power Systems, King Abdulaziz University, Jeddah 21589, \\ Saudi Arabia \\ Correspondence should be addressed to Jahin Al Hasan Joy; joy2003558@stud.kuet.ac.bd
}

Received 9 July 2021; Accepted 31 August 2021; Published 18 September 2021

Academic Editor: Dilbag Singh

Copyright (C) 2021 Ibrahim M. Mehedi et al. This is an open access article distributed under the Creative Commons Attribution License, which permits unrestricted use, distribution, and reproduction in any medium, provided the original work is properly cited.

\begin{abstract}
Today, there is a large increase in the demand for electricity. The transmission and distribution networks, however, cannot fulfill unbound demands due to the scarcity of resources. Power lines have losses which make the situation more unfavorable for maximum power transfer. Implementing a flexible AC transmission system (FACTS) is one of the best ways to reduce line losses. This paper proposes a FACTS-based method for minimizing the fault current in the system. Switchgear and protection equipment also perform better when this is done. Moreover, due to the reduced fault current of the switched system, a larger amount of power can be transmitted. Static synchronous series compensator (SSSC), static synchronous compensator (STATCOM), and unified power flow controller (UPFC) are evaluated in this case. With STATCOM and UPFC, fault currents are significantly reduced. Furthermore, STATCOM and UPFC can also reduce the fault currents in the power system in addition to voltage regulation and power flow control. A MATLAB/Simulink model is used to evaluate the model's feasibility.
\end{abstract}

\section{Introduction}

Humanity has been blessed with the greatest gift of all with electricity. Modern life would not be possible without electricity. Daily life cannot be lived without it. Electricity is the lifeblood of any economy and industry. Despite exponentially increasing power demand, transmission and distribution systems do not have the resources to meet those demands. To ensure reliable and quality electrical power services, the corresponding systems are constructed with care, designed carefully, and maintained appropriately. The occurrence of frequent faults is an obstacle to the comprehensive and reliable operation of the systems. Power system analysis considers the frequency of these faults very carefully [1]. There might be various causes of a fault, such as a short circuit, a natural calamity, an overload, or reckless maintenance. System failures may manifest themselves in several ways, such as a triple-phase failure, a single line to ground failure, and a double-line failure. In the present system, the faults contribute to a huge increase in the current level. Damage to power system equipment could cause the whole area to black out [2].

Fault current is defined as the instantaneous increase in current caused by a short circuit or other fault in a power system [3]. Short circuits frequently occur between the lines or lines and the ground in the three-phase transmission network [4]. During a short-circuit fault, the current can rise by up to 10 times the load current [5]. This will negatively 
impact the power network's reliability and efficiency. Distribution network and transmission system have widely implemented flexible AC transmission system (FACTS) to help improve and regulate credibility as well as exercise power [6].

The widely used FACTS devices in the transmission network are Static VAR compensator (SVC) [7], thyristor controlled phase shifting transformer (TCPST), thyristor controlled series capacitor or compensator (TCSC), STATCOM, SSSC, and UPFC [8-10]. Additionally, distribution STATCOM (DSTATCOM), dynamic voltage restorer (DVR) [11], and unified power quality conditioner (UPQC) are used in the distribution network. The operation of the FACTS devices is controlled by different controllers such as fuzzy controller [12, 13], adaptive controller [14], and PI controller [15]. A perfect placement of these FACTS devices gives maximum power quality improvement $[16,17]$. These FACTS devices can also be used to reduce the fault current in the system $[18,19]$. Researchers have considered the first-generation FACTS devices [18] and also reduced the voltage level for fault current reduction [19]. Furthermore, auxiliary equipment such as power electronic equipment-based fault current limiter (FCL) $[20,21]$ and superconducting fault current limiter (SFCL) $[22,23]$ have been used. However, now, without using an extra current limiter the second-generation FACTS devices can be used as fault current limiters keeping the voltage level constant.

By reducing fault current within half a cycle, these devices can drastically reduce failure rates. The protection system can be reduced in stress. In this way, we can utilize a low-rated protection system, which is incredibly economical. The FACTS system is used in this paper. Analysis of the performance of SSSC, STATCOM, and UPFC has been conducted as a fault current reduction device. IEEE 9-BUS 3 machine system has been selected. A MATLAB/Simulink environment was used for the whole simulation. We describe the proposed system's modeling in Section 2. FACTS controls are also included in this. There are plots for the simulation results in Section 3. In Section 4, we summarize our findings.

\section{System Modeling}

IEEE 9-BUS 3 machine system [24] is used as the basis for this system analysis. The system is connected to a number of FACTS devices for further analysis.

2.1. IEEE 9-BUS 3 Machine System. This system has three sources. There are three separate buses that connect these sources. Two of these three have been used in the bus, with one being a combination of solar panels and diesel generators. Another option is to use a diesel generator only. Each bus has three loads connected to it, respectively. Matlab/ Simulink was used to design this model. MATLAB is used to design the line parameters' model. Either in parallel or in series, the FACTS device is attached to the bus between 4 and 6. By deploying the FACTS devices in appropriate locations, the power system will be more secure since the bus voltage, power flow, and short circuit current will be controlled to the desired level [17]. Our FACTS device is connected to the load side in this paper. A circuit breaker is installed on both sides of the buses for the protection of the system. Circuit breakers automatically trip whenever a problem occurs, isolating the faulty component from the rest of the system. An outline diagram is provided in Figure 1.

2.2. FACTS Device Modeling. Two principles guide FACTS ${ }^{\prime}$ work. Shunt compensation and series compensation are the two types. Different types of FACTS devices are available based on construction and operation. Our paper implements SSSC, STATCOM, and UPFC. The following is a description of these FACTS devices' models and control schemes.

SSSC regulates and improves power flow in power grids by using a flexible AC transmission system [25]. Series compensation is the basis of SSSC. In series with the transmission line, it injects voltage into the system. The power source does not need to be active. Injecting voltages that are quadrature to line current is required. As a result, the transmission line's overall reactive voltage drop can either increase or decrease. VSC (voltage source converter) is a part of the SSSC. This VSC produces an AC voltage at the fundamental frequency by controlling the PWM signal according to the system parameters. As a result, the system's impedance can be controlled using the SSSC in series with it. As a result, reactive power compensation controls the flow of power through a transmission line.

The control system of SSSC in Figure 2 consists of a phase-locked loop (PLL), measurement system, voltage regulator, and PWM modulator. Reactive power control compensates the power flow through SSSC. A transmission line's active $(P)$ and reactive $(Q)$ power flows as follows:

$$
\begin{aligned}
& P=\frac{V_{1} V_{2}}{X} \sin \left(\delta_{1}-\delta_{2}\right)=\frac{V^{2}}{X} \sin \delta, \\
& Q=\frac{V_{1} V_{2}}{X}\left(1-\cos \left(\delta_{1}-\delta_{2}\right)\right)=\frac{V^{2}}{X}(1-\cos \delta),
\end{aligned}
$$

where $V_{1}$ and $V_{2}$ are the voltage values at the two ends and $X$ is the combined reactance of the transmission line and the SSSC. In order to simplify this, we will take $V$ as the magnitude of the voltage and $\delta$ as the magnitude of the phase difference. The PLL synchronizes with the positive sequence current component I in the control system. To send a signal to the regulator, the measuring system compares the voltage with a reference value. A PWM modulator control signal is generated from the signal from the regulator. Based on these pulses, the VSC output is generated via the PWM. The voltage output is used for fault correction in the system.

Shunt compensation is FACTS. Power flow is controlled by the STATCOM, and the power system's transient stability is improved [25]. Voltage source converter (VSC) is connected in shunt with the system. Controlling the VSC controls the flow of reactive power. Reactive voltages and currents are supplied or absorbed in order to balance out reactive power flows. Reactive power is generated when the voltage on the system is low. Alternatively, in the case of a 


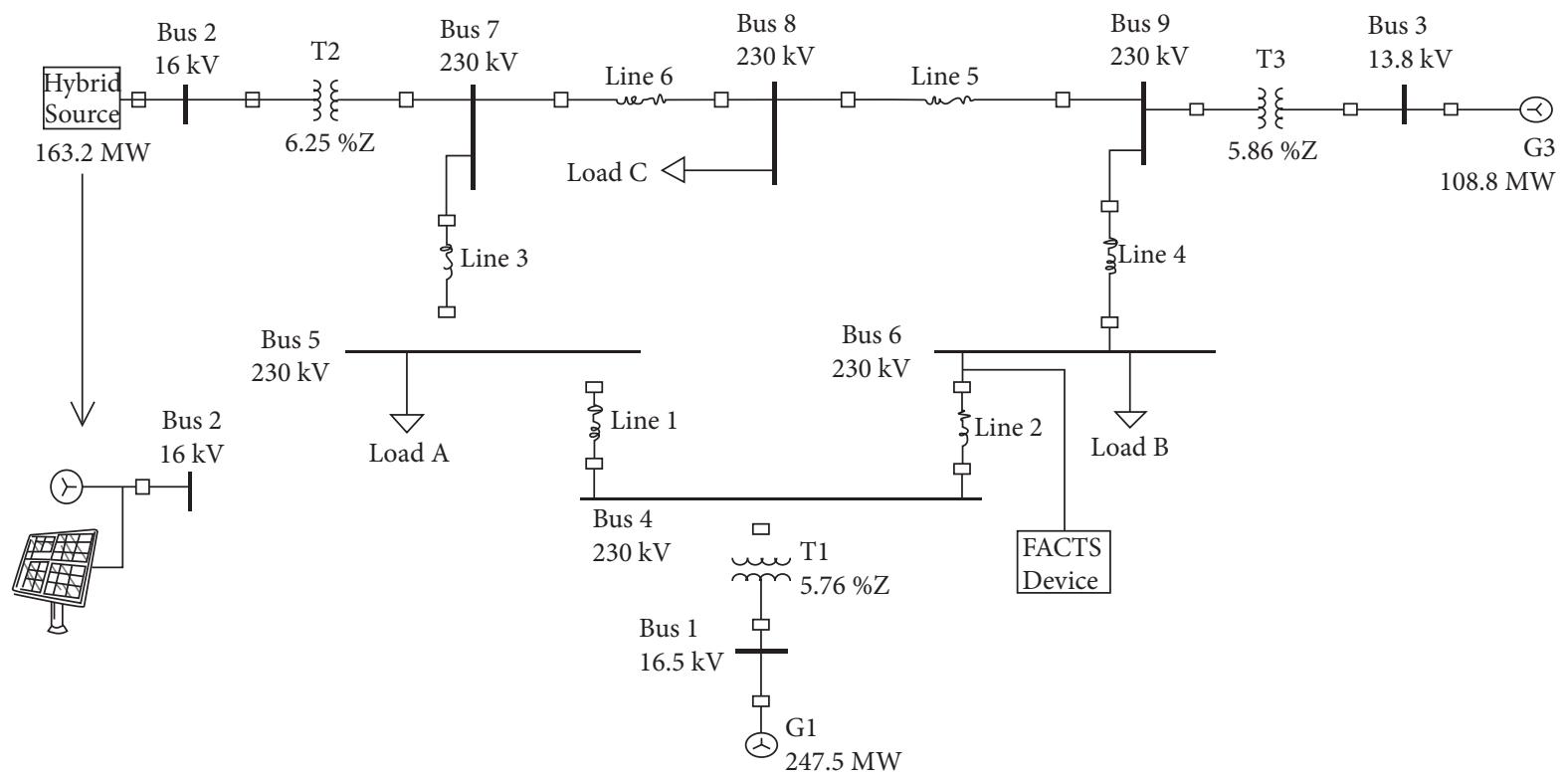

Figure 1: One-line diagram of the IEEE 9-bus 3machine system.

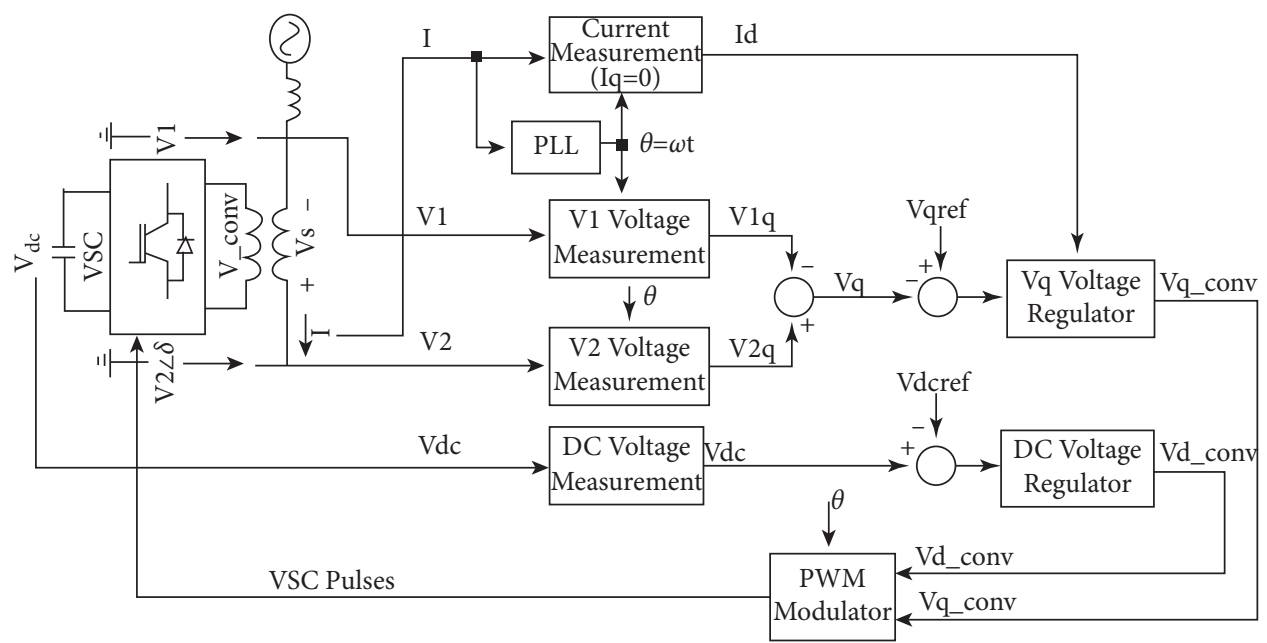

FIgURE 2: Control scheme of SSSC.

high-voltage system, the VSC absorbs the reactive power. Including a storage system in the device can enable a variety of special applications such as active power flow, power deregulation, and network security.

The control scheme in Figure 3 of STATCOM consists of a phase-locked loop (PLL), voltage and current measurement system, voltage and current regulator, and PWM modulator. By using a storage system, both active and reactive power can be compensated. In the STATCOM and power system, the active $(P)$ and reactive $(Q)$ power flows are given by

$$
\begin{aligned}
& P=\frac{V_{1} V_{2}}{X} \sin \delta, \\
& Q=\frac{V_{1}}{X}\left(V_{1}-V_{2} \cos \delta\right),
\end{aligned}
$$

where $V_{1}$ and $V_{2}$ are the voltages of the transmission line and the output voltage of the VSC, respectively, and $\delta$ is the phase difference. $X$ corresponds to the interconnection transformer's and filter's reactance.

PLLs consolidate the three-phase primary voltage on the positive component of $V_{1}$ in the control scheme. A signal is then sent to the voltage regulators based on the comparison with the reference value. This voltage regulator controls the current regulator based on its current component compared to the actual current component. By generating the PWM modulator signal from the current regulator, the VSC is controlled by a PWM signal. The VSC controls the flow of reactive current between the transmission line and STAT$\mathrm{COM}$. The current flow is given by

$$
I=\frac{V_{1} V_{2}}{X}\left(V_{1} \cos \delta-V_{2}\right) \text {. }
$$




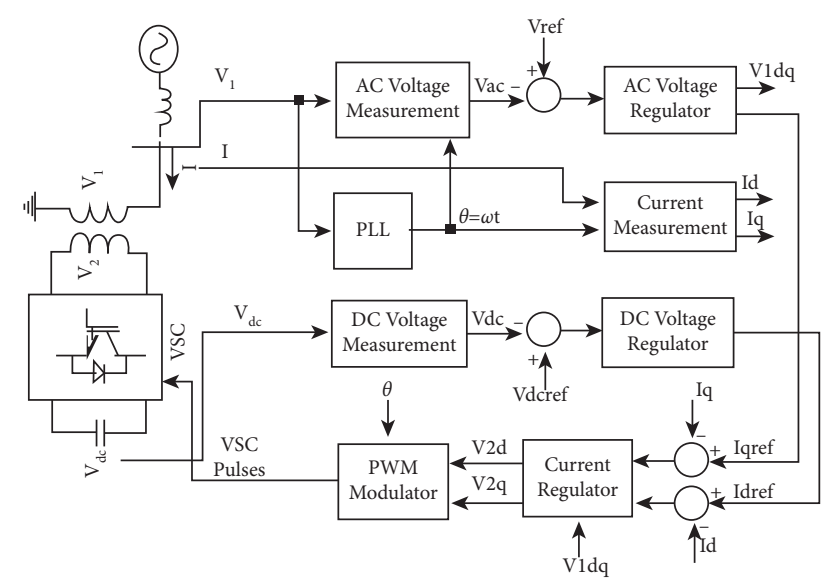

FIGURE 3: Control scheme of STATCOM.

The STATCOM and power system are controlled by the power flow controlled by the VSC. This method compensates the flow of reactive power.

UPFC is a specific type of FACT. STATCOM and SSSC are combined in the UPFC. That is, both series and shunt compensations are based on the working principle. The UPFC controls both active and reactive power flows and improves the stability of the power system [25]. Power flow control and voltage injection are the two main modes of operation for UPFCs. VSC2 generates or absorbs controllable reactive power to compensate for the reactive power flow. A DC terminal's real power demand is calculated from AC power exchanges at the transmission line by a VSC2. Once this DC demand of VSC2 has been met, VSC1 will again convert it into AC power. VSC1 can also provide shunt compensation by generating or absorbing controllable reactive power. A variation in the phase of the VSC output can also flow the active power.

Phase-locked loops (PLLs), voltage regulators, and PWM modulators comprise the UPFC control scheme shown in Figure 4. A VSC's active flow $(\mathrm{P})$ and reactive flow $(Q)$ are as follows:

$$
\begin{aligned}
& P=\frac{V_{2} V_{3}}{X} \sin \delta, \\
& Q=\frac{V_{2}}{X}\left(V_{2}-V_{3} \cos \delta\right) .
\end{aligned}
$$

A transmission line consists of two voltages, $V_{1}$ and $V_{2}$, and a phase difference, ${ }^{*} . X$ is the reactance between the transmission line and the UPFC. With PLL, voltage and current are synchronized in the positive sequence $(\mathrm{V}, \mathrm{I})$. These voltages are then compared to those of the reference value for the voltage injection mood. We have, nevertheless, used power flow control in this paper. Therefore, here we compute active and reactive power from voltage and current components. This comparison generates PWM control signal compared to the reference power value. Afterward, the VSCs are controlled by PWM signals. The transmission current is controlled by these VSCs. In a transmission line, the current flow is given by

$$
I=\frac{V_{1} V_{2}}{X}\left(V_{1} \cos \delta-V_{2}\right) .
$$

In this way, the power flow in the transmission line is compensated by absorbing or supplying the reactive current.

\section{Result and Discussion}

The simulation process is done in the MATLAB/Simulink environment. In the simulation, a discrete simulation type of the powergui block was taken to reduce the simulation time for both three phase and single phase, as shown in Figures 5 and 6. In each case, a short circuit fault was inserted at $t=0.5 \mathrm{sec}$. The fault was inserted at the load side in load B, i.e., Bus 6 . And, the fault current was measured in each case. In this setup, the fault current with different FACTS devices was also observed.

It is necessary to isolate the faulty part from the rest of the system using circuit breakers, but these circuit breakers are very expensive to operate at these enormous currents. The faulty part should be reduced in fault current. It is possible to use different FACTS devices to reduce the fault current. Below, we will discuss different FACTS devices and their effects.

3.1. With SSSC Connected. Bus 4 stops at SSSC and bus 6 stops at SSSC. To calculate the voltage loss in the transmission line, SSSC compares voltages between the two buses. The VSS and the capacitor voltage in SSSC control the PWM signals used to generate the VSC pulses. LSSC possesses the capability of supplying or absorbing voltage according to pulses generated by the system.

In Figure 7, we can see the current on bus 6. It is evident from the picture below that, at $t=0.5 \mathrm{sec}$, the peak value of fault current for the three-phase fault is almost identical to that without FACTS. This is because the SSSC acts as a source of voltage. In addition to changing the device's reactance, comparing two bus voltages changes the system's reactance as well. By doing so, it provides or absorbs the voltage to compensate for voltage fluctuations of the system. Therefore, there is not much of an impact on the system's current. It is also nearly the same as before when it comes to the fault current in the system. It is reduced by a very low value in this case. It is therefore not worthwhile to reduce the fault current of the system with SSSC.

\subsection{With STATCOM Connected. A STATCOM is a FACTS} device that is used in conjunction with a system. The bus 4 is connected to it here in shunt. From the current readings of the bus, the STATCOM calculates the current reference and compares this value to the actual current in the bus to establish the PWM control signal. Last, but not least, this signal regulates VSC pulses. A controllable current source is therefore created through this VSC.

As shown in Figure 8, with STATCOM connected with the system for three-phase fault inserted at $t=0.5 \mathrm{sec}$, bus 6 has the current wave shape. After $0.5 \mathrm{sec}$, the RMS value fault current peaks at $3118 \mathrm{~A}$, and after the transient period, it is 


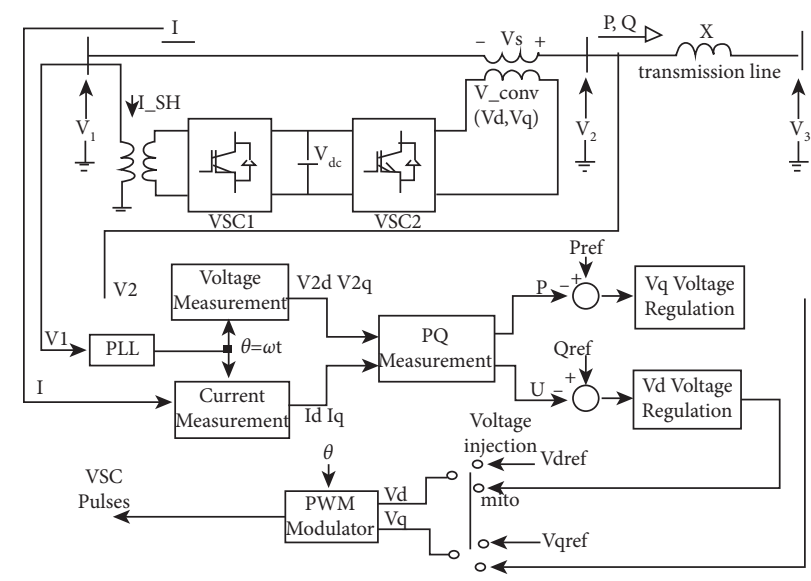

FIGURE 4: Control scheme of UPFC.

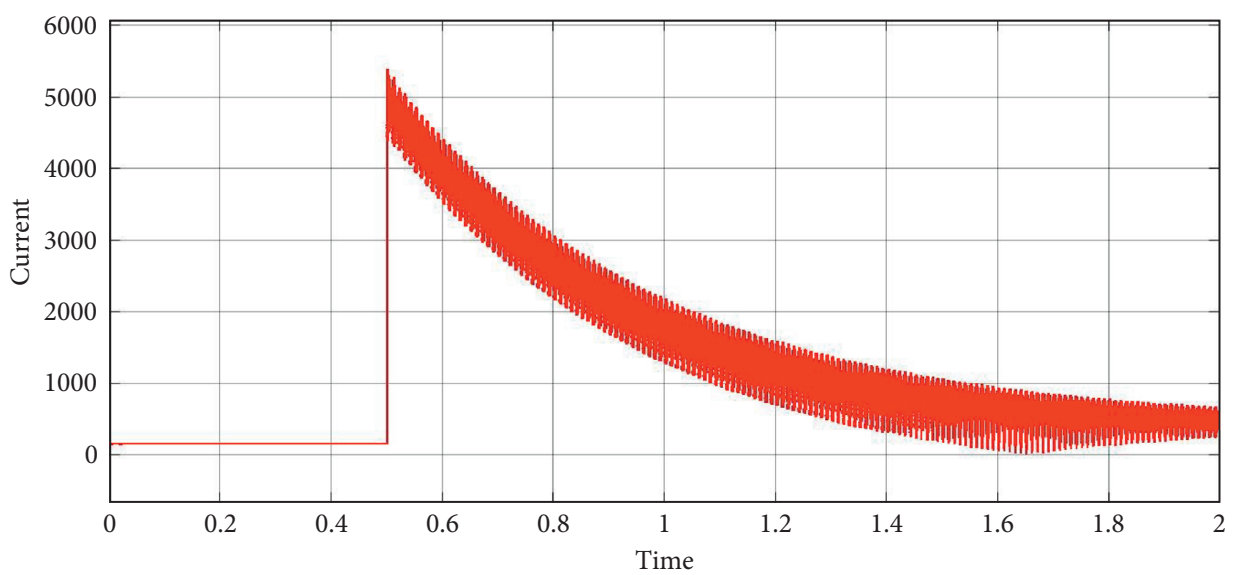

FIgURE 5: The current wave shape of bus 6 in RMS without FACTS devices for three-phase fault in load B inserted at $t=0.5$ sec.

592 A under steady state condition. This is evident from figure. A STATCOM absorbs fault current from the system here. As a reactive power, the device stores the current. The STATCOM acts as a current source in this way to reduce the fault currents. This case shows that the peak RMS fault current was reduced by over 2000 A.

The fault due to single line to ground fault can also be analyzed for STATCOM. Figure 9 shows the fault current of bus 6 in this case. Here, the RMS value of the fault current is 346 A under steady state condition.

3.3. With UPFC Connected. UPFC is a special type of FACTS device that uses both a series and shunt compensation technique. SSSC and STATCOM are combined to form UPFC. By calculating the voltage and current in the system, we can determine the real power as well as the reactive power. In the transmission system, the UPFC controls the reactive power flow from this power to the FACTS device.

There are two types of UPFC: voltage injection and power flow control. According to this paper, UPFC works as a flow control method. The peak RMS value of fault current measured at $t=0.5 \mathrm{sec}$ for the three-phase fault can be viewed in Figure 10. Figure 5 shows the original fault current in the absence of any FACTS devices, which is a very large value compared to this.

As well, we can compare UPFC performance when dealing with a single line and ground fault. A short circuit fault at bus 6 is shown in Figure 11. The peak RMS value of the fault current is also reduced to $758 \mathrm{~A}$ in a single line to ground fault, and it becomes $350 \mathrm{~A}$ at steady state. Compared to the original value, it is low. Transmission line losses are extremely high at normal fault current. UPFC absorbs the power from transmission lines to reduce fault current, thus compensating for this loss. Thus, the transmission line has a controlled power flow.

We can see from the above simulation results that the fault current of the transmission line can be reduced by using FACTS devices in the system. Comparing the current waveforms, the STATCOM and UPFC perform well in this case. Meanwhile, SSSCs are devices that are connected in series and are used for voltage stabilization and power flow control. As a result, it cannot be used to reduce fault currents.

STATCOM and UPFC clearly offer benefits for reducing fault current, as shown in Table 1. In this case, however, SSSC only acts as a voltage source in the system with very little effect on the system as a whole. UPFC also has better 


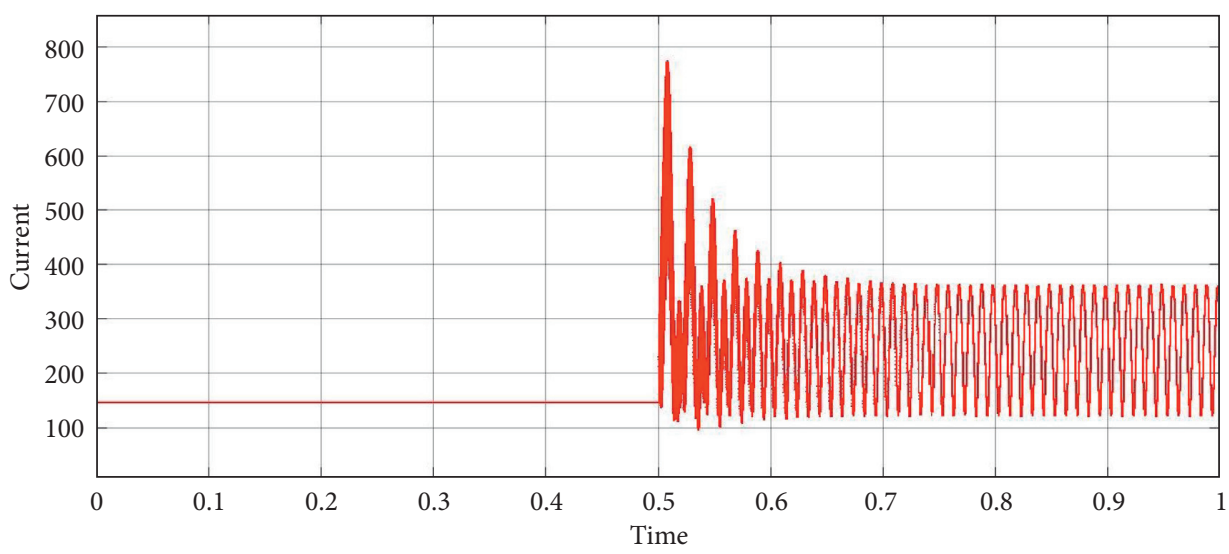

Figure 6: The current wave shape of bus 6 in RMS without FACTS devices for single line to ground fault in load B inserted at $t=0.5$ sec.

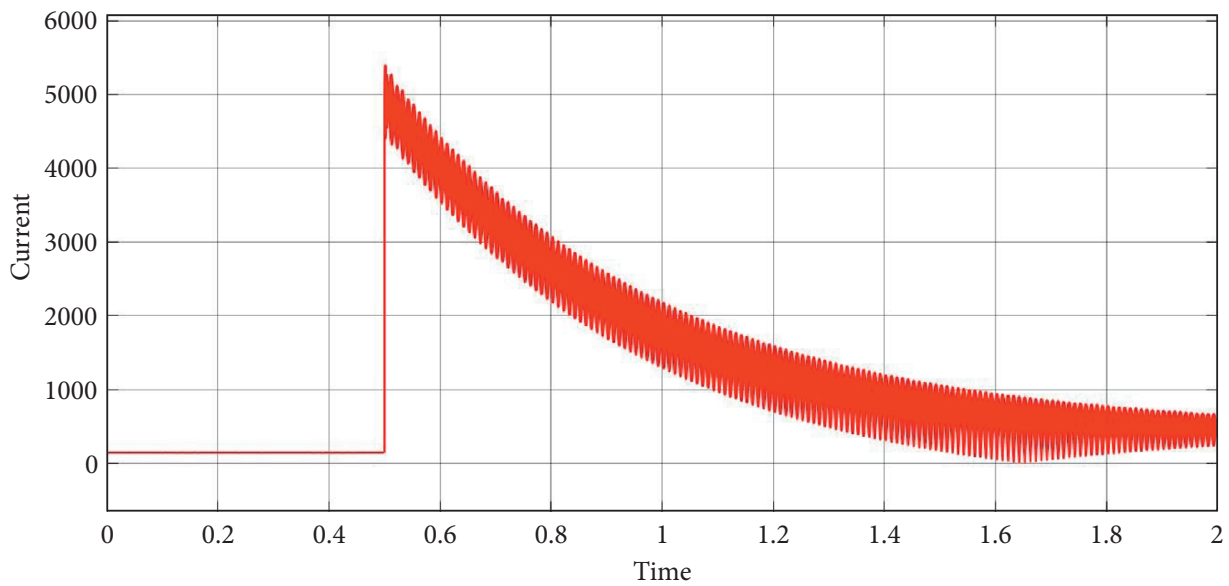

FIgURE 7: The current wave shape of bus 6 in RMS with SSSC connected for three-phase fault in load B inserted at $t=0.5$ sec.

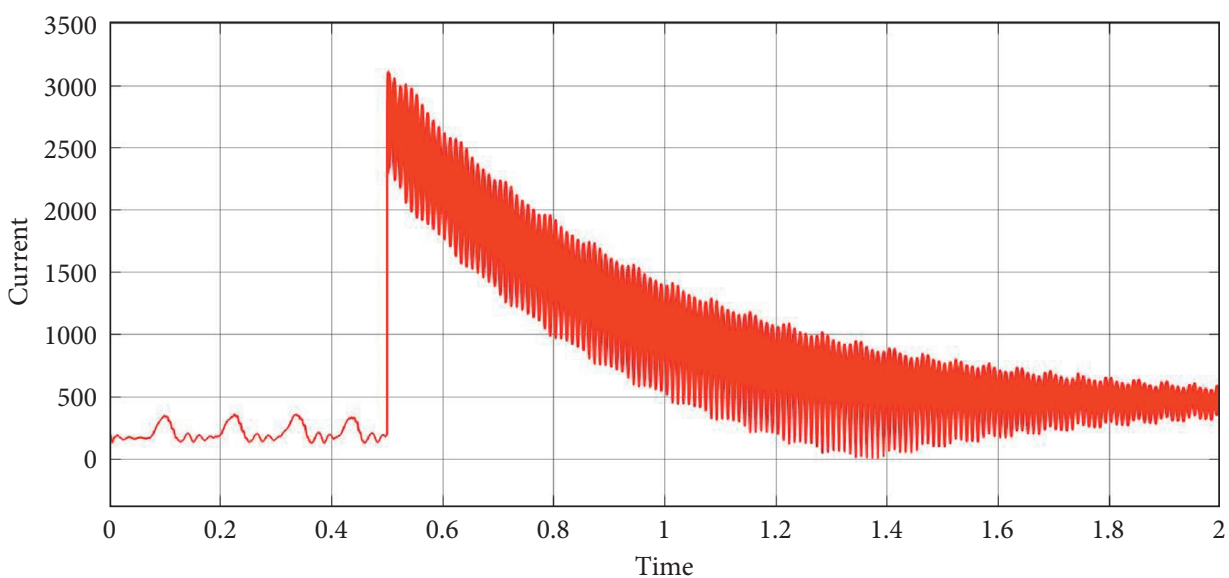

FIgURE 8: The current wave shape of bus 6 in RMS with STATCOM connected for three-phase fault in load B inserted at $t=0.5$ sec. 


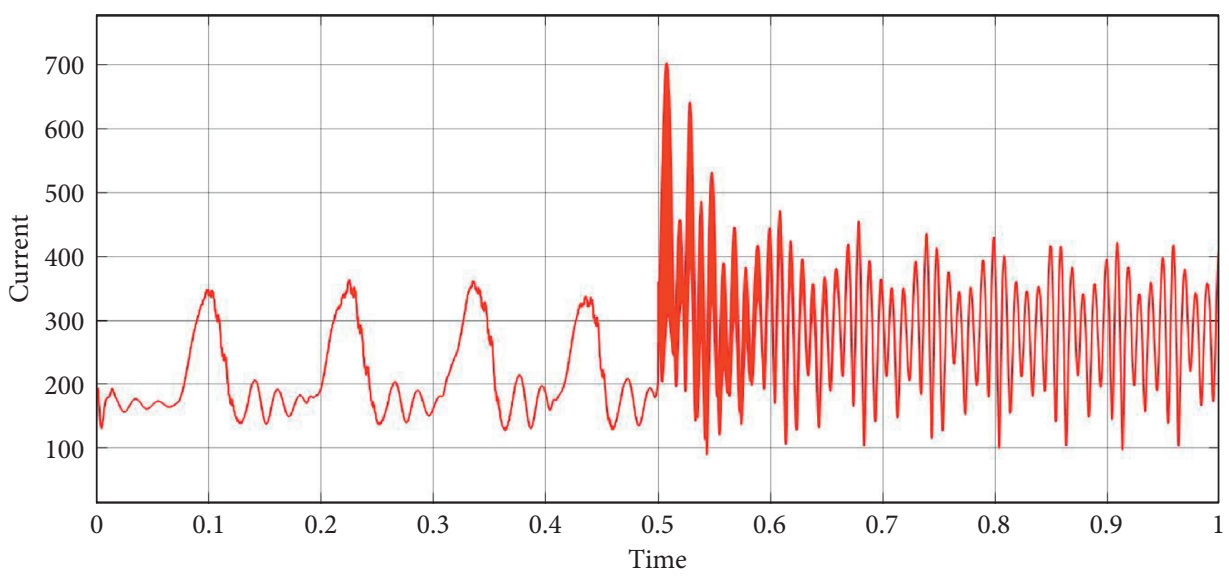

FIGURE 9: The current wave shape of bus 6 in RMS with STATCOM connected for single line to ground fault in load B inserted at $t=0.5$ sec.

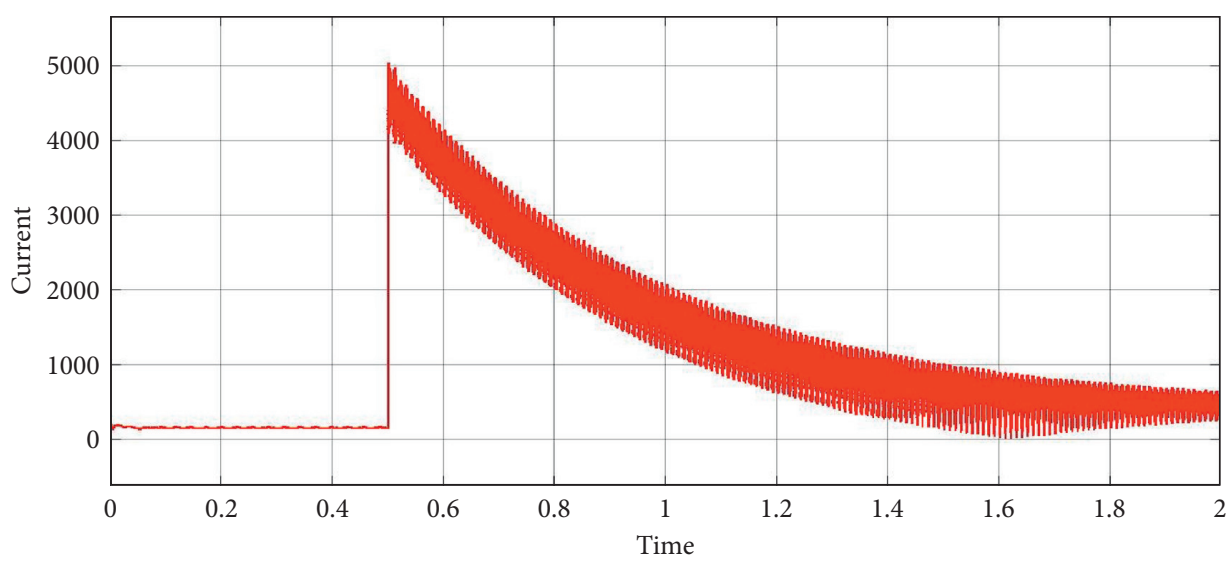

FIgURE 10: The current wave shape of bus 6 in RMS with UPFC connected for three-phase fault in load B inserted at $t=0.5$ sec.

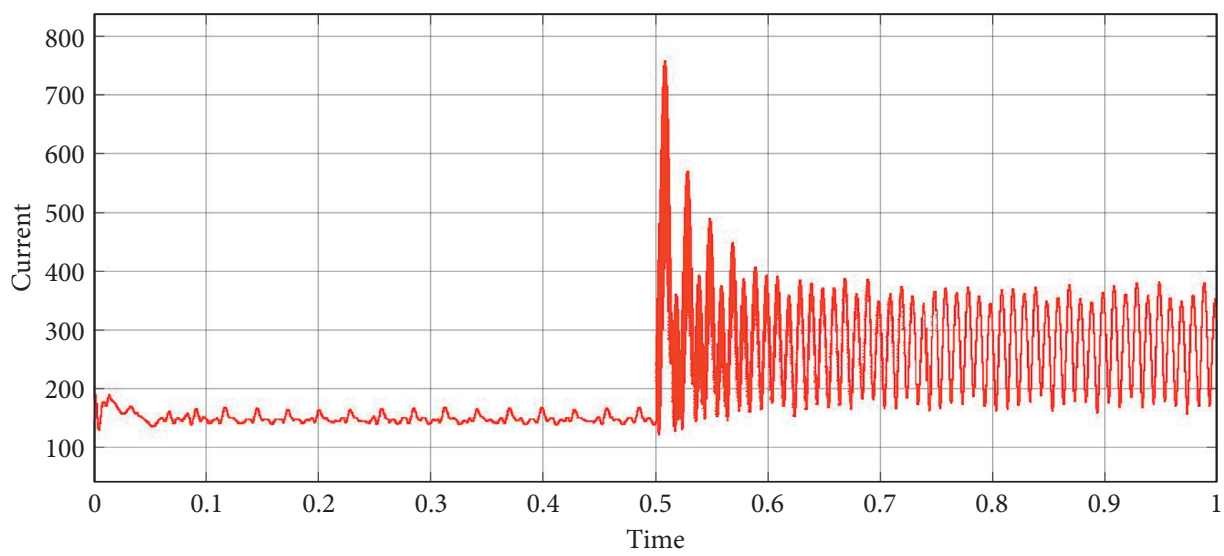

FIGURE 11: The current wave shape of bus 6 in RMS with UPFC connected for single line to ground fault in load B inserted at $t=0.5$ sec. 
TABLe 1: Effect of FACTS devices in peak fault current for different faults in Bus 6 .

\begin{tabular}{|c|c|c|c|c|c|}
\hline Fault type & Bus ID & $\begin{array}{c}\text { Without FACTS } \\
\text { (A in RMS) }\end{array}$ & $\begin{array}{c}\text { SSSC } \\
\text { (A in RMS) }\end{array}$ & $\begin{array}{l}\text { STATCOM } \\
\text { (A in RMS) }\end{array}$ & UPFC (A in RMS) \\
\hline \multirow{6}{*}{ Three-phase fault } & Bus 1 & 7210 & 7180 & 6518 & 6500 \\
\hline & Bus 2 & 5515 & 5510 & 4662 & 4540 \\
\hline & Bus 3 & 4377 & 4386 & 4041 & 4090 \\
\hline & Load A & 172 & 170 & 160 & 157 \\
\hline & Load B & 237 & 237 & 226 & 224 \\
\hline & Load C & 665 & 675 & 592 & 553 \\
\hline \multirow{6}{*}{ Single line to ground fault } & Bus 1 & 6138 & 5405 & 5350 & 5335 \\
\hline & Bus 2 & 6202 & 5985 & 5970 & 6090 \\
\hline & Bus 3 & 4754 & 4598 & 4335 & 4396 \\
\hline & Load A & 247 & 245 & 218 & 218 \\
\hline & Load B & 364 & 370 & 346 & 350 \\
\hline & Load C & 236 & 251 & 204 & 212 \\
\hline \multirow{6}{*}{ Double line to ground fault } & Bus 1 & 7706 & 7598 & 7600 & 7595 \\
\hline & Bus 2 & 6596 & 6681 & 6550 & 6530 \\
\hline & Bus 3 & 5258 & 5337 & 5180 & 5184 \\
\hline & Load A & 181 & 185 & 165 & 153 \\
\hline & Load B & 263 & 269 & 249 & 242 \\
\hline & Load C & 569 & 571 & 506 & 505 \\
\hline \multirow{6}{*}{ Line to line fault } & Bus 1 & 7831 & 7632 & 7249 & 7268 \\
\hline & Bus 2 & 6982 & 6860 & 5980 & 6356 \\
\hline & Bus 3 & 5556 & 5428 & 4515 & 5178 \\
\hline & Load A & 183 & 180 & 165 & 160 \\
\hline & Load B & 272 & 272 & 251 & 252 \\
\hline & Load C & 562 & 567 & 519 & 515 \\
\hline
\end{tabular}

performance in voltage control, impedance, phase angle control, and surge stabilization [25-27]. It is more suitable for all these applications to use UPFC rather than STATCOM.

\section{Conclusion}

Different FACTS devices have been evaluated as fault current limiters in this paper. The performance of the SSSC, STATCOM, and UPFC are being studied among several FACTS devices. SSSC does not contribute significantly to fault current and voltage regulation, whereas it focuses exclusively on reactive power flow. On the contrary, UPFC and STATCOM are able to reduce fault current besides correcting voltage and regulating current. STATCOM and UPFC absorb reactive power from the system in a manner that greatly reduces fault currents. Stability, transients, and voltage control are better achieved with UPFC than STATCOM. As a result, the system's critical clearing time will be lengthened due to the low fault current. The switchgear and protection system will not need to be changed, so it will be possible to transmit more power. By including FACTS in a transmission and distribution system, both economic benefits and reliability are provided.

\section{Data Availability}

No data were used to support this study.

\section{Disclosure}

A part of the content of this paper was presented in 18th International Multi-Conference on Systems, Signals and Devices (SSD), 22-25 March 2021, Monastir, Tunisia.

\section{Conflicts of Interest}

The authors declare that they have no conflicts of interest.

\section{Acknowledgments}

This research work was funded by Institutional Fund Projects, under Grant no IFPRC-040-135-2020. Therefore, the authors gratefully acknowledge technical and financial support from the Ministry of Education and King Abdulaziz University, Jeddah, Saudi Arabia.

\section{References}

[1] H. Schmitt, "Fault current limiters report on the activities of CIGRE WG A3.16," Proceedings of the IEEE PES General Meeting, vol. 5, 2006.

[2] L. Kovalsky, X. Yuan, K. Tekletsadik, A. Keri, J. Bock, and F. Breuer, "Applications of superconducting fault current limiters in electric power transmission systems," IEEE Transactions on Appiled Superconductivity, vol. 15, no. 2, pp. 2130-2133, 2005.

[3] Y. Xin, W. Gong, X. Niu et al., "Development of Superconducting Fault Current Limiters," in Proceedings of the 6th International Conference on Power System Technology, pp. 1-5, Chongqing, China, July 2006.

[4] R. F. Giese, Fault Current Limiters-A Second Look, Argonne National Laboratory, Paris, France, 1995.

[5] T. Yazawa, E. Yoneda, J. Matsuzaki et al., "Design and test results of $6.6 \mathrm{kV}$ high-Tc superconducting fault current limiter," IEEE Transactions on Appiled Superconductivity, vol. 11, no. 1, pp. 2511-2514, 2001. 
[6] R. K. Padiyar, FACTS Controllers in Power Transmission and Distribution, Anshan Publishers, Anshan, China, 1st edition, 2007.

[7] I. M. Mehedi, H. Bassi, M. J. Rawa et al., "Intelligent machine learning with evolutionary algorithm based short term load forecasting in power systems," IEEE Access, vol. 9, pp. 100113-100124, 2021.

[8] H. Mishra, F. Raza, and S. Khan, "Improvement of power system stability using FACTS controller," Lecture Notes in Electrical Engineering, vol. 756, pp. 225-236, 2021.

[9] A. Siddique, Y. Xu, W. Aslam, and F. M. Albatsh, "Application of series FACT devices SSSC and TCSC with POD controller in electrical power system network," in Proceedings of the 13th IEEE Conference on Industrial Electronics and Applications (ICIEA), Wuhan, China, June 2018.

[10] D. Prakash, "Enhancing stability of multi-machine IEEE 9 bus power system network using PSS," International Journal of Advanced Research in Electrical, Electronics and Instrumentation Engineering, vol. 4, no. 5, 2015.

[11] H. Suyono, L. M. Hayusman, and M. Dhofir, "Improvement of voltage sag mitigation using dynamic voltage restorer (DVR)," ARPN Journal of Engineering and Applied Sciences, vol. 10, no. 19, pp. 8684-8691, 2015.

[12] I. M. Mehedi, H. S. M. Shah, U. M. Al-Saggaf, R. Mansouri, and M. Bettayeb, "Adaptive fuzzy sliding mode control of a pressure-controlled artificial ventilator," Journal of Healthcare Engineering, vol. 2021, Article ID 1926711, 10 pages, 2021.

[13] I. M. Mehedi, Z. Salam, M. Z. Ramli et al., "Critical evaluation and review of partial shading mitigation methods for gridconnected PV system using hardware solutions: the modulelevel and array-level approaches," Renewable and Sustainable Energy Reviews, vol. 146, 2021.

[14] H. Makvandi, M. Joorabian, and H. Barati, "A new optimal design of ACD-based UPFC supplementary controller for interconnected power systems," Measurement, vol. 182, 2021.

[15] T. Singh, N. Saxena, M. Khurana, D. Singh, M. Abdalla, and H. Alshazly, "Data clustering using moth-flame optimization algorithm," Sensors, vol. 21, no. 12, p. 4086, 2021.

[16] H. R. Baghaee, M. Mirsalim, G. B. Gharehpetian, and A. K. Kaviani, "Security/cost-based optimal allocation of multi-type FACTS devices using multi-objective particle swarm optimization," Simulation, vol. 88, no. 8, pp. 999-1010, 2012.

[17] M. C. Das, R. Dash, S. C. Swain, and V. Subburaj, "Performance enhancement of PI-controller using SVM for DFIG-grid interconnected system," in Proceedings of the 2nd International Conference for Emerging Technology (INCET), pp. 1-6, Belgaum, India, May 2021.

[18] M. Zellagui, H. A. Hassan, A. Chaghi, and A. Ghorbani, “A comparative study of ground fault analysis for a practical case of a transmission line equipped with different series FACTS devices," Automatika, vol. 56, no. 3, pp. 262-274, 2017.

[19] R. L. Vasquez-Arnez, L. C. Zanetta Jr., and F. A. Moreira, "Effective limitation of line fault currents by means of the series-connected VSC-based facts devices," SBA: Controle \& Automação Sociedade Brasileira de Automatica, vol. 17, no. 4, pp. 459-468, 2006.

[20] H. Suyono, R. N. Hasanah, E. Kuncoro, and H. Mokhlis, "Modeling and analysis of fault current limiter as a shortcircuit protection device," International Conference on Electrical, Electronics and Information Engineering, vol. 18, pp. 43-48, 2017.

[21] M. E. Alshammari, M. A. M. Ramli, and I. M. Mehedi, "A new chaotic artificial bee colony for the risk-constrained economic emission dispatch problem incorporating wind power," Energies, vol. 14, no. 13, p. 4014, 2021.

[22] L. Ye and A. M. Campbell, "Case study of HTS resistive superconducting fault current limiter in electrical distribution systems," Electric Power Systems Research, vol. 77, no. 5-6, pp. 534-539, 2007.

[23] M. Tsuda, Y. Mitani, K. Tsuji, and K. Kakihana, "Application of resistor based superconducting fault current limiter to enhancement of power system transient stability," IEEE Transactions on Appiled Superconductivity, vol. 11, no. 1, pp. 2122-2125, 2001.

[24] S. Sharma, N. S. Velgapudi, and K. Pandey, "Performance analysis of IEEE 9 bus system using TCSC," Recent Developments in Control, Automation \& Power Engineering (RDCAPE), vol. 8, pp. 251-256, 2017.

[25] N. G. Hingorani and L. Gyugyi, Understanding FACTS: Concepts and Technology of Flexible AC Transmission Systems, IEEE Press Book, Piscataway, NJ, USA, 2000.

[26] A. R. Krishna and R. K. Reddy, "Power quality problems and it's improvement using FACTS devices," International Journal of Engineering Trends and Technology, vol. 4, no. 5, pp. 1462-1466, 2013.

[27] M. Kaur, D. Singh, V. Kumar, B. B. Gupta, and A. A. Abd ElLatif, "Secure and energy efficient-based E-health care framework for green internet of things," IEEE Transactions on Green Communications and Networking, vol. 5, no. 3, pp. 1223-1231, 2021. 